\title{
Modernization of The Management of a University Educational Structural Unit Based on The Distributed Leadership Model
}

\author{
Elena Nikolaevna Gevorkian ${ }^{1,2 *}$, Alexander Ilich Savenkov ${ }^{2,3}$, Mixail Lvovich Levitski ${ }^{2,4}$, \\ and Lora Narikbayeva ${ }^{5}$ \\ ${ }^{1}$ Doctor of economics, Academician of RAE, Moscow, Russia \\ ${ }^{2}$ Moscow City University, Moscow, Russia \\ ${ }^{3}$ Doctor of psychology, Corresponding member of RAE, Moscow, Russia \\ ${ }^{4}$ Doctor of pedagogy, Academician of RAE, Moscow, Russia \\ ${ }^{5}$ Doctor of pedagogy, Professor, Kazakh National Pedagogical University Named After Abai, Institute \\ Of Arts, Culture and Sports, Department of Music Education and Choreography, Almaty, \\ Kazakhstan
}

\begin{abstract}
The study proposes an original version of the reorganization of the management of an educational structural unit of a university based on the "distributed leadership model". The purpose of the study is to compare the effectiveness of bachelor's and master's programs in the traditional and based on the "distributed leadership model" management systems. The study showed that the qualitative transformation of the management of the university's educational unit based on the "distributed leadership model" made it possible to delegate a significant part of the teachers' managerial powers, which allowed positive changes in the effectiveness of education programs (quantitative and qualitative characteristics of applicants, improvement of the quality of teaching, the competitiveness of education programs etc.) implemented at the institute.
\end{abstract}

\section{Introduction}

The management system of universities and their structural divisions (departments, faculties, institutes, etc.) is traditionally very democratic. Teachers of higher education can rightfully be ranked as "creative class" [1], therefore, the maximum performance of the university can be achieved through wide delegation of administrative authority. The effective mechanism for increasing centers for making managerial decisions in organizations offers a "distributed leadership model" [2-8].

In the scientific literature, the "distributed leadership model" is usually described in the "managerial relay race" variant, when managerial powers are successively transferred from one team member to another $[4,6]$. In our work, under the supervision of the educational structural unit of the university (institute), different variant of the "distributed leadership model" was used, which assumes the maximum increase in the number of employees making

* Corresponding author: gevorcian@mgpu.ru 
managerial decisions. The purpose of the study is to compare the performance of bachelor's and master's programs in the traditional and based on the "distributed leadership model" management systems.

\section{Methods}

The base of the experimental work was the Institute of Pedagogy and Psychology of Education of the Moscow City University. The main hypothetical assumption was that attracting the largest possible number of employees of the institute to make managerial decisions will increase the effectiveness of education programs, improve the psychological climate in the team and, therefore, make the work of the institute more efficient.

Until the 2016-2017 academic year, the institute worked according to the traditional managerial model, which expressed monolithic management attitudes. Such a management system made it possible to gradually increase the quantitative and qualitative characteristics of a set of applicants, improve the level of teaching, and ensure the competitiveness of education programs.

From 2016-2017 to the 2019-2020 academic years, the institute reorganized the management system based on the "distributed leadership model". The comparative assessment of the performance of the institute in the context of the traditional management model and in the conditions of the "distributed leadership model" was made based on objective data on the following indicators:

- quantitative and qualitative characteristics of a set of applicants for programs (annually, a rating of education programs is formed at the university as part of the admission company: bachelor's programs - according to the results of the USE (Unified State Exam); master's according to the number of applicants for one place);

- the quality of education programs (criteria: by student ratings, teachers' compliance with labor subject, the stability of the student population);

- the effectiveness of the work of the supervisor of education programs (criteria: professional training; fame; involvement; discipline);

- teachers' responsibility for the quality of their educational and scientific work (criteria: professional training; fame; involvement; discipline);

- competitiveness of the education programs of the institute within the university and in the metropolis (the criterion is the popularity of the program in the professional community and among applicants).

The central link in the reorganization was the endowment of a large number of teachers with real managerial authority. The institute introduced mandatory guidance not only for master's programs, but also for bachelor's programs. Supervisors of education programs were delegated the maximum managerial powers to enable them to improve the educational process, independently select the most qualified teachers and motivated students. To solve this problem, five related departments of the institute were combined into three: pedagogy, psychology and methodology. At the same time, the educational department of the institute was transformed into a "department for ensuring the educational process". We emphasize that enlarging and renaming departments was not about optimization, but consolidating at the organizational and verbal levels, a global semantic reorganization of the activities of the professional unit. The supervisor of the department, in our management system, is relieved of one of the main duties - to distribute the workload. Under the new conditions, their function is to stimulate the development of scientific schools, improve skills and promote its teachers. The post of deputy for educational work in these conditions is abolished, and the deputy for scientific work is transformed into the scientific supervisor of the department.

As a result, the decision-making center is shifted from the directorate of the institute and the heads of departments to the supervisors of education programs. The supervisor of the 
education program takes full responsibility for its effectiveness and receives the authority to attract teachers.

The selection of the supervisor of the education program was carried out based on the following requirements:

1. Professional training of the supervisor (diploma of basic education) and, most importantly, the profile of their scientific interests should correspond with the direction and profile of the education program. Objective criteria: topics of defended theses, main publications in scientific highly rated journals, the degree of their demand by specialists (links to the RSCI (Russian Science Citation Index), Scopus, Web of Science).

2.Fame - recognition in the professional community. Objective criteria: Hirsch indices in modern scientometric databases (RSCI, Scopus, Web of Science).

3.Involvement in the implementation of the education program. Objective criteria: supervisor's intellectual and emotional desire for maximum professional returns, determined by the degree of interest in working with colleagues and students within the framework of this topic, the desire to improve and develop their education program as well as to identify themself with this topic as the supervisor of a scientific school.

4.Discipline - traditionally understood as an attitude towards one's professional duties. Objective criteria: quality of educational and scientific work with students, adherence to the schedule and preparation of current documentation.

Since the supervisor of the education program has a direct interest in improving its qualitative and quantitative characteristics achieved by the quality of teaching, they select teachers according to similar criteria:

1. professional training - compliance of scientific and pedagogical achievements of a teacher with the profile of the subject taught; topics of defended theses, main publications in scientific highly rated journals (RSCI, Scopus, Web of Science);

2. fame - recognition in the professional community, evaluated by Hirsch indices in modern scientometric databases (RSCI, Scopus, Web of Science);

3. involvement - teacher's intellectual and emotional aspiration, motivating them to maximize professional return, is determined by the degree of interest in the implementation of the education program, the desire to improve and develop it, to identify themself as a member of the education program team;

4. discipline - attitude to their professional duties, criteria: the quality of educational and scientific work with students, adherence to the schedule, preparation of current documentation.

As a result of this approach, there is no uniform distribution of the workload, and the system of real competition is being built at the institute: someone is gaining one and a half or two, and someone has a quarter of the salary, there are those who have to change jobs.

\section{Results}

The transformation of the management model allowed us to achieve the following results:

- Improved quantitative and qualitative characteristics of a set of applicants. The average exams for bachelor's programs increased annually starting from 2017, the maximum growth was recorded in 2019 , and it turned out to be higher by 3.1 points than in 2018 . In the master's programs, the competition is also progressing (the master's program "management in education" has become the leader of the university's admission company; a good competition has also been observed for other institute programs).

- The responsibility of supervisors and teachers in improving existing education programs, developing and implementing new ones has increased. Supervisors develop and annually adjust curricula using the "library of modules" operating at the institute $[9,10]$. The subjects in the modules usually have the author's names given to them by the leading 
teachers; this is allowed by the current educational standard and allows dismissing teachers who are not narrow specialists in a taught subject.

- The quality of teaching has improved by reducing the number of "relay teachers". The supervisor of education programs attract teachers whose scientific work corresponds to the profile of taught subjects. Failure to comply with this rule will quickly affect the relevance of the program to potential applicants;

- The responsibility of teachers for the quality of their educational and scientific work has increased, supervisors invite only those who are able to work effectively within the framework of the topic;

- The quality of final qualification works was improved by creating at the institute a "committee on the ethics of psychological and pedagogical research", which received special powers to manage the quality of scientific developments [11].

- The education programs of the institute have become more competitive, inside the university and among the programs of other universities in Moscow.

\section{Discussion}

The proof of the effectiveness of applying the "distributed leadership model" in the management of the institute is complicated by the fact that most of the transformations carried out are focused on qualitative changes that gradually increase quantitative indicators [12-16]. However, even at a period of several years, tangible positive quantitative changes were obtained. An important result of the reorganization was the improvement of the emotional climate in the team as well as the increase of employee interest. The study revealed that the qualitative transformation of the institute's management based on the "distributed leadership model" made it possible to delegate a significant part of the teaching staff managerial responsibilities, which affected the effectiveness of education programs. The assignment of a significant part of the teaching staff with administrative powers delegating to them the right to make real management decisions led to qualitative changes in increasing the degree of their involvement in the educational activities of the institute and contributed to improving the overall psychological climate in the team.

\section{Conclusion}

The study allows us to conclude that the "distributed leadership model" implemented at the institute is an effective tool for improving management efficiency.

The study showed that qualitative transformations in the institute's management system based on the "distributed leadership model" made it possible to achieve positive changes in the activities of education programs (quantitative and qualitative characteristics of applicants, improvement of the quality of teaching, competitiveness of education programs, etc.) implemented at the institute.

The endowment of a significant part of teachers with managerial powers and the transfer to them of the right to make real management decisions, has led to an increase in their involvement in the educational activities of the institute and an improvement in the overall psychological climate in the team. The search for the most effective management models for educational departments requires further longitudinal research.

\section{References}

1. R. Florida, The Rise of the Creative Class (Mann, Ivanov and Ferber, Moscow, 2016)

2. M.R. Belbin, Management Teams: Why they succeed or fail (Kiwits, London, 2009) 
3. M. Malone, I. Salim, Y. Van Geest, Exponential Organizations: Why new organizations are ten times better, faster, and cheaper than yours (and what to do about it) (Alpina Digital, Moscow, 2014)

4. K.M. Ushakov, Public education 9-10(1465), 67-73 (2017)

5. Farson R., Management of the absurd, (Sofia, Kiev, 2001)

6. S.R. Filonovich, Russian Journal of Management 1(2), 3-24 (2003)

7. Leadership Development Trends 2019: a survey report based on a study of 200+ organizations (Mercer Mett, 2019) Available at: https://www.mmc.com/content/dam/mmcweb/insights/publications/2019/sep/Leadership.Dvelopment.Trends.2019.pdf

8. I. Letina, S. Liu, N. Netzer, Theoretical Economics 15(2), 477-509 (2020)

9. E.N. Gevorkyan, A.I. Savenkov, A.S. Lvova, Designing a modular construction of the process of teaching future teachers in a magister's program, In the book Current problems of professional and higher education: state and assessment (Moscow, 2019)

10. A.S. Lvova, O.A. Lyubchenko, Principles of the modular organization of the educational process in the magistracy, In the collection: Training of managers for the capital education system: experience and prospects (Moscow, Moscow City Pedagogical University, 2016)

11. E.N. Gevorkyan, A.I. Savenkov, A.M. Dvoinin, Pedagogy 11, 66-73 (2018)

12. V.I. Savinkov, P.A. Baklanov, G.V. Osipov, Social assessment of quality and the relevance of education: textbook (Yurait, Moscow, 2019)

13. A.F. Shvets, Theoretical Economics 1(49), 84-88 (2019)

14. G. Alaev, L. Ruzhanskaya, E. Yakimova, D. Zubakina, N. Kostyleva, Espacios 39(11), (2018)

15. S. Filonovich, L. Tatarchenko, L. Ruzhanskaya, L. Pliner, Management and leadership development needs: the case of Russia, Business and Society: Making Management Education Relevant for the 21st Century (Springer International Publishing, 2018)

16. J.A. Kaufman, SAGE Open 9(1), 1-6 (2019) 